\section{C.B. МЕЗЕНЦЕВА}

Хабаровский государственный институт культуры

2. Хабаровск, Россия

ORCID: 0000-0002-4258-5436

mezenceva-sv@yandex.ru

\section{SVETLANA V. MEZENTSEVA}

Khabarovsk State

Institute of Culture

Khabarovsk, Russia

ORCID: 0000-0002-4258-5436

mezenceva-sv@yandex.ru

\section{Новая культура трансляции знаний в условиях цифровой образовательной среды творческого вуза (об опыте работы в системах Moodle и Moodle Music)}

В работе ставится проблема формирования новой культуры трансляции знаний. Рассматривается современное состояние системы вузовского образования в условиях цифровой образовательной среды. В этой связи проводится расширенный анализ учебно-методического обеспечения дисциплин, связанных с применением музыкально-компьютерных технологий (МКТ) в творческих вузах, оценивается качество и методы преподавания, осознания роли новых цифровых образовательных технологий и МКТ как перспективного инструмента расширения информационного пространства творческого вуза в условиях функционирования высокотехнологичной цифровой образовательной среды.

На основе новых возможностей современных компьютерных методов работы со звуком, потенциала современных компьютерных нотных редакторов, компьютерных программ, связанных со звукозаписью и звуковоспроизведением, у студентов-музыкантов вырабатываются навыки использования возможностей современных компьютерных методов работы со звуком в процессе музыкально-

\section{A New Culture of Broadcasting Knowledge in the Conditions of the Digital Educational Environment of an Artistic University (about the Experience of Working in the Moodle and Moodle Music Systems)}

The work raises the problem of forming a new culture of knowledge transmission. The current state of the system of higher education in a digital educational environment is examined. In this regard, an extended analysis of educational and methodological support of disciplines related to the use of music computer technologies (MCT) in artistic universities is carried out, the quality and methods of teaching, the awareness of the role of new digital educational technologies and MCT as a promising tool for expanding the information space of the artistic university in the context of the functioning of a high-tech digital educational environment. Based on the new capabilities of modern computer methods of working with sound, the potential of modern computer music editors, computer programs related to sound recording and sound reproduction, student musicians develop skills to utilize the capabilities of modern computer methods of working with sound in the process of musical and artistic activity, the potential of a modern musician develops - whether a performer, a composer, a music theorist, or teacher - by using music and computer programs in various fields of professional 
творческой деятельности, развивается потенциал современного музыканта исполнителя, композитора, теоретика, преподавателя - с использованием музыкально-компьютерных программ в различных сферах профессиональной деятельности. Автором статьи также анализируются возможности систем Moodle и Moodle Music в творческом вузе.

\section{Ключевые слова:}

культура трансляции знаний, цифровая образовательная среда, творческий вуз, современные информационные технологии, музыкально-компьютерные технологии, Moodle, Moodle Music. activities. The author of the article also analyzes the capabilities of the Moodle and Moodle Music systems in a creative university.
Keywords:

culture of knowledge transmission, digital educational environment, creative university, modern information technologies, music and computer technologies, Moodle, Moodle Music.

Для цитирования/For citation:

Мезенцева С.В. Новая культура трансляции знаний в условиях цифровой образовательной среды творческого вуза (об опыте работы в системе Moodle и Moodle Music) // ИКОНИ / ICONI. 2020. № 3. C. 80-86. DOI: 10.33779/2658-4824.2020.3.080-086.

$\mathrm{B}$ настоящее время новое информационное общество диктует особые требования к организации образовательной среды и к учебно-методическому обеспечению учебного процесса. Цифровые технологии стремительно внедряются во все сферы нашей жизни, в том числе и в образование. Родители привыкают к электронным дневникам, преподаватели имеют личные кабинеты и персональные сайты. На различных платформах создаются виртуальные учебники и методические материалы, внедряются продукты, обеспечивающие возможность эффективного самообучения (мобильные обучающие технологии, приложения для планшетных устройств).

Понятие «Цифровая образовательная среда» достаточно молодое, с неустоявшимися определениями и формами практической реализации. Рядом с ним фигурируют близкие понятия, такие как «информационное образовательное про- странство», «сетевые образовательные ресурсы», «электронная образовательная среда», «школа цифрового века», а также инновационные формы подачи дидактических источников: электронный учебник, облачно-ориентированные и online педагогические ресурсы и т. п.

В рамках данной работы акцентируется проблема постепенного формирования новой культуры трансляции знаний в условиях цифровой образовательной среды [1]. В современном обществе происходит неизбежная эволюция способов коммуникации, формируется новая информационная научная система, новое педагогическое сознание (см., например, работы [5; 6]). Кажется, уходят в прошлое рассуждения о необходимости противостоять компьютеризации и внедрению новых технологий в образовательное пространство. Находят определённый компромисс с музыкально-компьютерными технологиями (МКТ) исполнители академической музыки, композиторы, 
музыковеды, искусствоведы [5; 9]. В настоящее время активно изучается влияние компьютерных технологий на современную музыкальную культуру и обучение [3; 10]. Думается, что в ближайшем будущем электронные учебники [8] и интерактивные сетевые технологии [6; 7] будут являться неотьемлемой частью информационного образовательного пространства [11], новым видом трансляции знаний станут дистанционные технологии, современные формы преподнесения учебных материалов и проверки их усвоения (контроля). Современные цифровые технологии и МКТ позволяют организовать обучение в Сети и обеспечить коммуникацию с различными участниками «культурного диалога». Новейшие компьютерные продукты представляются уникальными инструментами передачи информации, необходимыми не только для повышения качества современного процесса образования, но и для формирования толерантной среды, улучшения качества образования, поиска современных систем обучения, эффективного культурного обмена. В современных условиях представляется перспективным расширение информационного поля, систем дистанционного обучения, МКТ, цифрового пространства.

Кроме того, экстренное введение режима нового формата передачи знаний в период мировой пандемии 2020 года убедительно продемонстрировало необходимость быть подготовленными в этом отношении, отодвигая на второй план все рассуждения о нужности и важности такого типа образования в целом, о его подводных камнях, трудностях, мнимых и реальных опасностях. Потребовался срочный переход учреждений культуры и образования на иную платформу.

Многие российские вузы внедряют модульную объектно-ориентированную дистанционную учебную среду Moodle. Эта система может быть использована для организации учебного процесса с применением образовательных техно- логий удалённого подключения для очной и заочной форм обучения, а также курсов повышения квалификации преподавателей. Moodle является относительно простой, но достаточно удобной платформой. Все права управления принадлежат администратору, который заводит курсы, журналы и другие элементы и закрепляет их за педагогами. Также он устанавливает конфигурацию сайта, его цветовое решение, шрифты, расположение объектов на страницах, имеет возможность вводить дополнительные модули, расширяя функциональные возможности системы дистанционного образования. А вот контент курсов полностью зависит от преподавателя, которому для начала необходимо зарегистрироваться и получить возможность редактирования с помощью встроенного редактора. Педагог имеет полный контроль над формированием курса, заполнением всех доступных ему элементов.

Система удобна не только преподавателям, но и студентам: каждый слушатель курса может в любой момент получить учебную информацию, проанализировать её, ответить на вопросы, выполнить задания, а кроме того, отследить свою текущую и промежуточную успеваемость. Эта информация конфиденциальна и не доступна другим слушателям. Важно отметить возможность использования языковых пакетов для работы иностранных студентов. Система дистанционного обучения Moodle предлагает большой набор интерактивных элементов и позволяет пользователям взаимодействовать друг с другом через чат, блог, форум, вики.

Конечно, даже молодым преподавателям непросто вникнуть в особенности системы и свободно ею пользоваться. Для начала педагогам можно приступить к заполнению электронных журналов, параллельно подготавливая лекции, семинары, методические материалы, индивидуальные и групповые задания для Moodle. По-прежнему актуальной 
остаётся тема обновления методических материалов. Понятие «электронный учебник» в настоящее время ещё достаточно расплывчато и применяется, скорее, как собирательное, обобщающее. По сути, это обучающая информация, размещённая в сети Internet в свободном или закрытом (ограниченном) доступе. Несомненно, это новый жанр и новая технология подачи и обработки. Отдельной проблемой становятся вопросы дистанционных технологий в музыкальном образовании. Известно, что в нашей стране акцент ставится на личностно-ориентированный подход, личный контакт и большое количество индивидуальных занятий. Думается, что в дистанционную среду более логично впишется формат теоретических дисциплин, а практические творческие занятия, как известно, невозможно оставить без ежеурочного личного контакта педагога и ученика. Интересно отметить, что Moodle содержит отдельный инструментарий в помощь музыканту (педагогу и обучающемуся) - Moodle Music. Это свободно распространяемая онлайн-среда для изучения теории музыки и тренировки слуха. Требуется регистрация, которая не составляет особого труда. Moodle Music содержит нотный редактор с руководством по его использованию. Нотатор позволяет набрать нотный пример, прослушать его, отредактировать. Педагог может создать небольшой нотный пример в качестве задания по музыкально-теоретическим дисциплинам. Этот пример будет наделён уникальным веб-адресом, который получит обучающийся. После выполнения задания ответ сохраняется, а для проверки сохранённого выполненного задания отправляется ссылка на него. Moodle Music предлагает проверить свои слуховые возможности в 15-минутном тесте, который включает в себя ритмические рисунки, мелодии, интервалы, гаммы, аккорды, задания по названиям нот и т. п. Отдельная закладка посвящена написанию канонов.
Определённые проблемы связаны с тем, что текст заданий в Moodle Music переводится с английского языка автоматически и достаточно приблизительно. Нужно приспособиться к форме заданий и их формулировкам. В целом сама попытка приблизить музыкантов к музыкально-компьютерным технологиям заслуживает внимания, а возможности Moodle Music могут быть применены в педагогической и творческой практике. Возможно представление контента на разных языках, что удобно для работы с иностранными студентами. Напрашивается ассоциация с приложением «Абсолютный слух" (на базе операционной системы Андроид), которое позволяет развивать музыкальные способности. Программа предоставляет базовые музыкально-теоретические знания о нотах, аккордах и интервалах. Содержит задания с возрастающей степенью сложности: ритмические и мелодические диктанты, определение на слух и построение интервалов, аккордов, ладов.

Пытаясь осмыслить информационную цивилизацию, учёные обращаются к опыту традиционной передачи знаний и опыта. Проявляющиеся всё сильнее процессы глобализации в современном обществе неизменно повышают внимание исследователей к традиционным культурам. Передача знаний, умений и навыков (как сейчас говорится, освоение компетенций) в традиционной культуре происходит прежде всего через непосредственный контакт и общение. До недавнего времени такая трансляция знаний и опыта была основной и в системе образования (пожалуй, только заочная форма обучения, по сути, являлась неким симбиозом дистанционной и очной форм контактирования). Однако с течением времени и под влиянием непреодолимых обстоятельств (например, пандемии) постепенно формируется новая культура трансляции знаний, привычные практики обучения уступают место новым способам передачи знаний. Современное 
информационное общество в период глобализации меняется стремительно.

Таким образом, неизбежны процессы технологизации современной культуры и образования. На наших глазах формируется особая культурная среда, специфическое образовательное пространство, новая культура трансляции знаний и опыта. В условиях цифровой образовательной среды творческого вуза международное сотрудничество выходит на другой уровень: ещё недавно перспектива, например, дистанционной сдачи государственной итоговой аттестации бакалаврами и магистрами из Китая творческих направлений подготовки в российском вузе не представлялась реальной. Теперь мы имеем и такой опыт, и обновленную культуру трансляции знаний. Развиваются МКТ - перспективный инструмент расширения информационного пространства творческого вуза в условиях функционирования высокотехнологичной цифровой образовательной среды. На основе новых возможностей, связанных с освоением современных компьютерных методов работы со звуком, нотных редакторов (нотаторов),
МКТ-программ звукозаписи и звуковоспроизведения, у студентов-музыкантов вырабатываются навыки использования методов работы со звуком в процессе музыкально-творческой деятельности, развивается потенциал музыканта нового поколения - исполнителя, композитора, теоретика, преподавателя, применяющего полученные знания в различных сферах профессиональной деятельности [2-4].

На помощь вузовской системе творческого образования пришли преимущества Moodle и Moodle Music, опыт применения которых демонстрирует их удобство, универсальность для разных типов задач: дистанционная вступительная кампания, итоговая государственная аттестация, текущий образовательный процесс для очной и заочной форм обучения. Конечно, ничто и никогда не заменит личного контакта в тендеме «ученик-учитель». Однако нельзя отрицать факта формирования новой культуры трансляции знаний в условиях цифровой образовательной среды современного вуза и, в целом, в системе образования в мире.

\section{ת литерАтурА}

1. Алиева И.Г., Горбунова И.Б., Мезенцева С.В. Музыкально-компьютерные технологии как инструмент трансляции и сохранения музыкального фольклора (на примере Дальнего Востока России) // Проблемы музыкальной науки. 2019. № 1 (34). С. 140-149.

DOI: 10.17674/1997-0854.2019.1.140-149.

2. Горбунова И.Б. Архитектоника музыкального звука // ИКОНИ, 2019. № 3. С. 112-128. DOI: 10.33779/2658-4824.2019.3.112-128.

3. Горбунова И.Б. Компьютерная студия звукозаписи как инструмент музыкального творчества и феномен музыкальной культуры // Общество: философия, история, культура, 2017. № 2. С. 87-92.

4. Горбунова И.Б. Методические аспекты толкования функционально-логических закономерностей музыки и музыкально-компьютерные технологии: системы музыкальной нотации // Общество: социология, психология, педагогика, 2016. № 10. С. 69-77.

5. Горбунова И.Б. Музыкально-компьютерные технологии как новая обучающая и творческая среда // Современное музыкальное образование - 2002: материалы Международной научно-практической конференции. Российский государственный педагогический университет им. А.И. Герцена, Санкт-Петербургская государственная консерватория им. Н.А. Римского-Корсакова / под общ. ред. И.Б. Горбуновой. СПб., 2002. C. 161-169. 
6. Горбунова И.Б., Помазенкова М.С. Музыкально-компьютерные и облачноориентированные технологии в системе современного музыкального образования // Научное мнение. 2015. № 3-2. С. 68-82.

7. Мезенцева С.В. Облачно-ориентированные технологии как новый метод взаимодействия культур в сфере высшего музыкально-педагогического образования // Педагогика искусства: сетевой электронный научный журнал. 2018. № 1.

URL: http://www.art-education.ru/electronic-journal/oblachno-orientirovannye-tehnologii-kaknovyy-metod-vzaimodeystviya-kultur-v (Дата обращения: 05.09.2020).

8. Мезенцева С.В. Сетевой электронный учебник как новое средство трансляции знаний (из опыта работы в вузе с иностранными студентами из КНР) // Мир науки, культуры, образования, 2018. № 1 (68). С. 246-248.

9. Gorbunova I.B. Music Computer Technologies in the Perspective of Digital Humanities, Arts, and Researches // Opcion. 2019. V. 35. No. S24, pp. 360-375.

10. Gorbunova I.B. New Tool for a Musician. International Conference Proceedings, Paris, France. 2018, pp. 144-149.

11. Gorbunova I.B., Zalivadny M.S. The Integrative Model for the Semantic Space of Music: Perspectives of Unifying Musicology and Musical Education. Problemy muzykal'noj nauki / Music Scholarship. 2018. № 4 (33), pp. 55-64. DOI: 10.17674/1997-0854.2018.4.055-064.

Об авторе:

Мезенцева Светлана Владимировна, кандидат искусствоведения, доцент, заведующая кафедрой искусствоведения, музыкально-инструментального и вокального искусства, Хабаровский государственный институт культуры (680045, г. Хабаровск, Россия),

ORCID: 0000-0002-4258-5436, mezenceva-sv@yandex.ru

\section{$\mu$ REFERENCES $\sim$}

1. Alieva I.G., Gorbunova I.B., Mezentseva S.V. Muzykal'no-komp'yuternye tekhnologii kak instrument translyatsii i sokhraneniya muzykal'nogo fol'klora (na primere Dal'nego Vostoka Rossii) [Musical Computer Technologies as an Instrument of Transmission and Preservation of Musical Folklore (by the Example of the Russian Far East)]. Problemy muzykal'noj nauki / Music Scholarship, 2019. No. 1 (34), pp. 140-149. DOI: 10.17674/1997-0854.2019.1.140-149.

2. Gorbunova I.B. Arkhitektonika muzykal'nogo zvuka [The Architectonics of Musical Sound]. ICONI, 2019. No. 3, pp. 112-128. (In Russ.) DOI: 10.33779/2658-4824.2019.3.112-128.

3. Gorbunova I.B. Komp'yuternaya studiya zvukozapisi kak instrument muzykal'nogo tvorchestva i fenomen muzykal'noy kul'tury [The Computer Recording Studio as an Instrument of Musical Creativity and a Phenomenon of Musical Culture]. Obshchestvo: filosofiya, istoriya, kul'tura [Society: Philosophy, History, Culture]. 2017. No. 2, pp. 87-92.

4. Gorbunova I.B. Metodicheskie aspekty tolkovaniya funktsional'no-logicheskikh zakonomernostey muzyki i muzykal'no-komp'yuternye tekhnologii: sistemy muzykal'noy notatsii [The Methodological Aspects of the Interpretation of the Functional-Logical Laws of Music and Musical Computer Technologies: Systems of Musical Notation]. Obshchestvo: filosofiya, istoriya, kul'tura [Society: Philosophy, History, Culture]. 2016. No. 10, pp. 69-77.

5. Gorbunova I.B. Muzykal'no-komp'yuternye tekhnologii kak obuchayushchaya i tvorcheskaya sreda [Music Computer Technologies as a New Educational and Creative Media]. Sovremennoe muzykal'noe obrazovanie - 2002: materialy Mezhdunarodnoy nauchno-prakticheskoy konferentsii [Contemporary Musical Education - 2002: Materials from the International Scholarly-Practical Conference]. Herzen State Pedagogical University of Russia, St. Petersburg Rimsky-Korsakov State Conservatory. Edited by I.B. Gorbunova. St. Petersburg, 2002, pp. 52-55. 
6. Gorbunova I.B., Pomazenkova M.S. Muzykal'no-komp'yuternye i oblachno-orientirovannye tekhnologii v sisteme sovremennogo muzykal'nogo obrazovaniya [Music Computer and CloudOriented Technologies in the System of Contemporary Musical Education]. Nauchnoe mnenie [Scientific Opinion]. 2015. No. 3-2, pp. 68-82.

7. Mezentseva S.V. Oblachno-orientirovannye tehnologii kak novyy metod vzaimodeystviya kul'tur v sfere vysshego muzykal'no-pedagogicheskogo obrazovaniya [Cloud-Oriented Technologies as a New Method of Interaction between Cultures in the Sphere of Higher Musical and Pedagogical Education]. Pedagogika iskusstva: setevoy elektronnyy nauchnyy zhurnal [The Pedagogic of Arts: Network Scholarly Journal]. 2018. No. 1. URL: http://www.art-education.ru/electronic-journal/ oblachno-orientirovannye-tehnologii-kak-novyy-metod-vzaimodeystviya-kultur-v (Access date: 05.09.2020).

8. Mezentseva S.V. Setevoy elektronnyy uchebnik kak novoe sredstvo translyatsii znaniy (iz opyta raboty v vuze s inostrannymi studentami iz KNR) [Online Electronic Textbook as a New Means of Transmitting Knowledge (from the Experience of Working at a University with Foreign Students from China)]. Mir nauki, kul'tury, obrazovaniya [The World of Science, Culture and Education]. 2018. No. 1 (68), pp. 246-248.

9. Gorbunova I.B. Music Computer Technologies in the Perspective of Digital Humanities, Arts, and Researches. Opcion. 2019. V. 35. No. S24, pp. 360-375.

10. Gorbunova I.B. New Tool for a Musician. International Conference Proceedings, Paris, France. 2018, pp. 144-149.

11. Gorbunova I.B., Zalivadny M.S. The Integrative Model for the Semantic Education. Problemy muzykal'noj nauki / Music Scholarship. 2018. № 4 (33), pp. 55-64. DOI: 10.17674/1997-0854.2018.4.055-064.

About the author:

Svetlana V. Mezentseva, Ph.D. (Arts), Associate Professor, Head of the Department of Art Studies, Musical Instrumental and Vocal Art, Khabarovsk State Institute of Culture (680045, Khabarovsk, Russia),

ORCID: 0000-0002-4258-5436, mezenceva-sv@yandex.ru

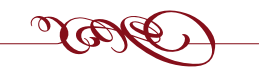

